\title{
A community-based study on prevalence and correlates of erectile dysfunction among Kinondoni District Residents, Dar Es Salaam, Tanzania
}

Pedro Pallangyo ${ }^{1,2^{*}}$, Paulina Nicholaus ${ }^{1}$, Peter Kisenge ${ }^{1}$, Henry Mayala ${ }^{1}$, Noel Swai ${ }^{1}$ and Mohamed Janabi ${ }^{1}$

\begin{abstract}
Background: Globally, erectile dysfunction burden (ED) is rising appreciably and it is projected to affect about 332 million men by the year 2025. This rise is attributable to the rising incidence of conditions associated with ED including obesity, diabetes, hypertension, coronary artery disease and depression. We conducted this community-based screening to elucidate on the prevalence of ED and its associated factors among men residing in an urban community in Tanzania.

Methods: We conducted a cross-sectional community-based study and interviewed 441 men aged at least 18 years. Diabetes and hypertension were defined as per the International Diabetes Federation (IDF) and the 7th Report of the Joint National Committee (JNC 7) respectively. The 5-item version of the International Index of Erectile Function (IIEF-5) Scale was used to assess for erectile dysfunction. Multivariate logistic regression analyses were performed to explore the factors associated with ED.

Results: The mean age was 47.1 years, $57.6 \%$ had excess body weight, $8.2 \%$ had diabetes and $61.5 \%$ had high blood pressure. Overall, $24 \%(106 / 441)$ of men in this study had some form of ED. Participants with age $\geq 55$, positive smoking history, obesity, diabetes and hypertension displayed highest rates of ED in their respective subgroups. However, age $\geq 40$ and diabetes were ultimately the strongest factors for ED after multivariate logistic regression analyses, (OR 5.0, $95 \% \mathrm{Cl} 2.2-11.2, p<0.001$ and $\mathrm{OR} 5.3,95 \% \mathrm{Cl} 2.2-12.7, p<0.001$ respectively).

Conclusion: Erectile dysfunction affects about a quarter of adult men living in Kinondoni district. Old age, obesity, smoking, hypertension and diabetes have the potential to increase the odds of ED up-to 5 times. In view of this, men with diabetes and hypertension should be offered screening services and treatment of ED as an integral component in their management.
\end{abstract}

Keywords: Erectile dysfunction, Diabetes, Hypertension, Excess body weight, Community-based

\section{Plain English summary}

Erectile dysfunction (ED) is defined as persistent inability to attain and/or maintain an erection sufficient for satisfactory sexual activity. ED is associated with old age and comorbidities including diabetes and hypertension amongst others. The incidence of $\mathrm{ED}$ is increasing

\footnotetext{
* Correspondence: pedro.pallangyo@gmail.com

${ }^{1}$ Department of Adult Cardiovascular Medicine, Jakaya Kikwete Cardiac Institute, P.O. Box 65141, Dar es Salaam, Tanzania

${ }^{2}$ Unit of Research, Jakaya Kikwete Cardiac Institute, P.O. Box 65141, Dar es Salaam, Tanzania
}

globally and this is attributed to the aging population and the increase in the incidence of diabetes and hypertension. We aimed to determine the burden of ED among male residents of Kinondoni district, Dar es Salaam Tanzania. We recruited and interviewed 441 men aged at least 18 years. We utilized the 5-item version of the International Index of Erectile Function (IIEF-5) Scale for erectile dysfunction assessment. We defined diabetes and hypertension according to the International Diabetes Federation and the 7th Report of the Joint National Committee (JNC 7) respectively. 
About a quarter of all men had some form of ED. Old age and diabetes were associated with a 5 times increased likelihood for having ED. We concluded that ED is a common problem among men of reproductive age and that men particularly those with diabetes and hypertension should be offered screening services and treatment of ED as an integral component in their management.

\section{Background}

Erectile dysfunction (ED) is defined as persistent inability to attain and/or maintain an erection sufficient for satisfactory sexual activity [1]. Despite its benign nature, ED has the potential to impair personal interactions, quality of life and well-being of both patients and their partners [2-4]. The rates of ED increase with age almost always indicating endothelial dysfunction [5-14]. Furthermore, ED is associated with a number of medical conditions or their treatment including diabetes mellitus, hypertension, coronary artery disease and depression [15-22].

Establishing the burden of ED in the community is challenging and most clinicians lack adequate skills in detecting and/or managing it [23, 24]. The reported rates worldwide have a wide variability ranging between $2 \%$ and $90 \%$ depending on the age, race, comorbidities, hospital- versus community-based, assessment tool, and geographical location of the population studied $[6-8,12$, 25-38]. With the rising of comorbidities associated with ED worldwide, it is projected that its incidence will rise appreciably and that by year 2025, 332 million men will have some form of ED [39]. Similar to other developing nations, Tanzania is also witnessing an upsurge of noncommunicable diseases with ED as an inevitable complication. Little is known about the community burden of ED in Tanzania. To elucidate on the prevalence of ED and its associated factors in a Tanzanian community we undertook this cross-sectional study among Kinondoni district men.

\section{Methods}

\section{Study procedures \& definition of terms}

We conducted this 4-days community-based crosssectional screening among men residing in Kinondoni district, Dar es Salaam, Tanzania in January 2016. Four hundred forty-one men of African descent aged at least 18 years were recruited and screened for erectile dysfunction. Participants were consented to participate in the study after they voluntarily came to the screening grounds for an organized general health check-up. Interviewers, mainly clinicians and nurses from the Jakaya Kikwete Cardiac Institute (JKCI) and Mwananyamala District Hospital were recruited and trained to administer the questionnaire and perform anthropometric, blood pressure (BP) and random/fasting blood glucose
(RBG/FBG) measurements. Weight and height were measured with standard scales and BMI was calculated by a ratio of weight (in kilograms) to height (in meters) squared. WHO BMI cut-off values were used to define underweight, normal, overweight and obese [40]. Smoking history was sought and participants were categorized as current, past or a never smoker. Diabetes was diagnosed using $\mathrm{RBG} \geq 11.1 \mathrm{mmol} / \mathrm{L}$ and/or $\mathrm{FBG} \geq 7 \mathrm{mmol} / \mathrm{L}$ [41]. Prediabetes was defined as FBG of 5.6-6.9 mmol/L and/or RBG of 7.8-11.0 mmol/L [41]. Blood pressure was measured by digital BP machines where a systolic blood pressure (SBP) $<120 \mathrm{mmHg}$ and a diastolic blood pressure (DBP) $<80 \mathrm{mmHg}$ defined normotension. Prehypertension was defined by SBP of $120-139 \mathrm{mmHg}$ or DBP of $80-89 \mathrm{mmHg}$, while SBP $\geq 140 \mathrm{mmHg}$ or DBP $\geq 90 \mathrm{mmHg}$ indicated hypertension [42]. The validated Swahili-translated 5-item version of the International Index of Erectile Function (IIEF-5) Scale was used to assess for erectile dysfunction [43-46]. The IIEF-5 Scale categorizes ED into five categories depending on the score i.e. 22-25: no ED, 17-21: mild ED, 12-16: mild to moderate ED, 8-11: moderate ED, 5-7: severe ED.

\section{Sample size calculations and recruitment process}

This study was conducted in Kinondoni district which has an adult ( $\geq 18$ years) population of about 1.633 million, $48.5 \%$ of whom are males. Overall, we aimed to screen (for hypertension and diabetes) a number representing at least $0.1 \%$ of the district's total population i.e. $\geq 1633$ persons. As this was the first local community-based study intending to investigate on the burden of ED, the authors hypothesized the prevalence to be $50 \%$ and so it was predetermined that a minimum of 396 men (i.e. $50 \%$ of the estimated 792/1633 men to be interviewed) will be assessed for ED. However, we exceeded the target and screened 1826 persons of whom 882 (48.3\%) were males. Our new minimum target for ED screening was then raised to 441 (i.e. $50 \%$ of the recruited 882/1826 men), which is the exact number that comprised this study.

\section{Statistical analysis}

Continuous variables are summarized and presented as means $( \pm \mathrm{SD})$ while categorical variables are displayed as frequencies (percentages). Chi square tests and Student's $T$-test were used in comparison of categorical and continuous variables respectively. Bivariate analyses were performed to determine factors associated with ED. Significant factors on bivariate analysis were included in a logistic regression model to control for confounders. Odd ratios with $95 \%$ confidence intervals and $p$-values are reported. STATA v.11.0 was used for analysis, significance was set at $p<0.05$ and all analyses were two-sided. 


\section{Results}

Socio-demographic and clinical characteristics of 441 study participants is displayed in Table 1 . The mean age was $47.1( \pm 15.4)$ years and $63.7 \%$ were aged 40 years and above. $53.8 \%$ had completed primary school, $71 \%$ were married, and $14 \%$ ever smoked. The mean BMI was $26.6( \pm 5.3) \mathrm{kg} / \mathrm{m}^{2}$ and $57.6 \%$ of individuals had excess body weight (i.e. BMI $\geq 25$ ). The mean blood glucose level was $6.1( \pm 2.2) \mathrm{mmol} / \mathrm{L}$ and $8.2 \%$ had type2 diabetes mellitus. The mean SBP and DBP were 146 $( \pm 32) \mathrm{mmHg}$ and $91( \pm 20) \mathrm{mmHg}$ respectively and $61.5 \%$ had hypertension.

Table 1 Socio-Demographic \& Clinical Characteristics of Study Participants $(N=441)$

\begin{tabular}{|c|c|}
\hline Characteristic & n (\%) \\
\hline \multicolumn{2}{|l|}{ Age groups } \\
\hline 18-39 & $160(36.3 \%)$ \\
\hline $40-54$ & $135(30.6 \%)$ \\
\hline$\geq 55$ & $146(33.1 \%)$ \\
\hline \multicolumn{2}{|l|}{ Education level } \\
\hline None & $12(02.7 \%)$ \\
\hline Primary & $237(53.8 \%)$ \\
\hline Secondary & $139(31.5 \%)$ \\
\hline University & $53(12.0 \%)$ \\
\hline \multicolumn{2}{|l|}{ Marital status } \\
\hline Single & $95(21.6 \%)$ \\
\hline Married & $313(71.0 \%)$ \\
\hline Divorced & $24(05.4 \%)$ \\
\hline Widowed & 9 (02.0 \%) \\
\hline \multicolumn{2}{|l|}{ Smoking status } \\
\hline Non-smoker & $379(86.0 \%)$ \\
\hline Current smoker & $9(02.0 \%)$ \\
\hline Past smoker & $53(12.0 \%)$ \\
\hline \multicolumn{2}{|l|}{ BMI status } \\
\hline Underweight & $14(03.2 \%)$ \\
\hline Normal & $173(39.2 \%)$ \\
\hline Overweight & $154(35.0 \%)$ \\
\hline Obese & $100(22.6 \%)$ \\
\hline \multicolumn{2}{|l|}{ Blood Sugar Range } \\
\hline Normal & $344(77.9 \%)$ \\
\hline Prediabetes & $61(13.9 \%)$ \\
\hline Diabetes & $36(08.2 \%)$ \\
\hline \multicolumn{2}{|c|}{ Blood Pressure Range } \\
\hline Normal & $60(13.6 \%)$ \\
\hline Prehypertension & $110(24.9 \%)$ \\
\hline Hypertension & $271(61.5 \%)$ \\
\hline
\end{tabular}

Overall, $24 \%(106 / 441)$ of men in this study had some form of ED. Of these, 9(8.5\%) had the mild form, 24 (22.6\%) mild-moderate form, 40 (37.8 \%) moderate form, and 33 (31.1 \%) had the severe form. Prevalence of ED increased with increase in age and weight i.e. $37 \%$ and $32 \%$ of those aged $\geq 55$ and obese respectively had ED compared to $10.6 \%$ and $18.1 \%$ among those aged $18-39$ years and normal BMI, $(p<0.001$ and $p<0.01$ respectively), Fig. 1. Men with a positive smoking history had a $40 \%$ increased likelihood for ED compared to never smokers, (OR 1.4, 95\%CI 0.7-2.5, p>0.05). $63 \%$ of men with diabetes had ED compared to $30.4 \%$ with prediabetes and $19.1 \%$ with normal blood glucose, $(p<$ 0.01 and $p<0.001$ respectively). Participants with prehypertension (20.2\%) and hypertension (29.3\%) had significantly higher ED rates compared to normotensive persons $(8.3 \%), p<0.05$ and $p<0.001$ respectively.

Six variables including age, BMI, physical activity, smoking, hypertension, and diabetes status underwent bivariate analyses to assess if they have associations with ED. Four variables including age, BMI, hypertension and diabetes status revealed significant associations and these were added in a logistic regression model for further analysis. Table 2 displays results of multivariate logistic regression analysis. Men aged 40 years and above displayed a 5 times increased likelihood of having ED compared to those younger than 40 years, (OR 5.0, $95 \%$ CI 2.2-11.2, $p<0.001)$. Likewise, diabetes was associated with a 5 times increased odds of having ED, (OR 5.3, $95 \%$ CI 2.2-12.7, $p<0.001$ ).

\section{Discussion}

Nearly a quarter of men in this present study had ED with over two-thirds exhibiting the moderate to severe form. Our findings are close to a Chinese study by Bai et al. which produced a prevalence of $28.3 \%$ [47]. A wide variability in the prevalence of ED from $13.2 \%$ [48] in Egypt to 51.3 [25] in Singapore observed among studies $[12,25,40,49]$ is largely a result of variabilities in population characteristics and tools used for ED assessment among studies. Old age has been consistently shown to be a strong predictor of ED [25]. In this study, the rate of ED among participants aged 55 and above was three times compared to those in the age group 18-39 years. These findings echo the results of a landmark Massachusetts Male Aging Study [25] among others [2, 18, 29]. Aging is associated with comorbidities resulting into atherosclerosis and ultimately vascular dysfunction with ED as one of the manifestations [50].

Obesity was significantly associated with ED on bivariate analyses in this study. Such findings are in unison with Moreira [12] et al. study in which obesity proved to be a significant predictor on bivariate analysis but lost its significance after multivariate analysis. A study by 
Prevalence of ED by Age

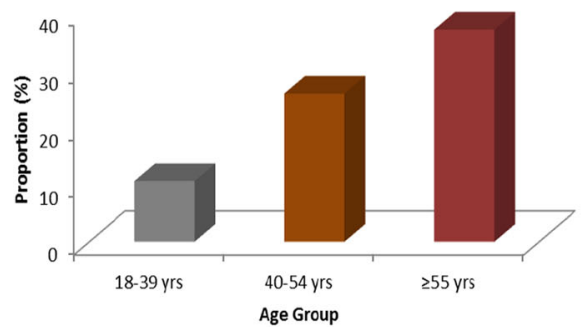

Prevalence of ED by Diabetes status

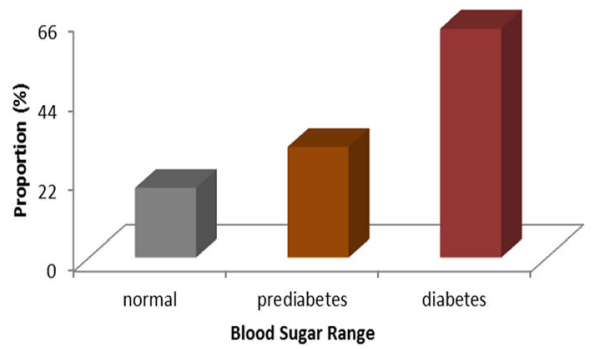

Prevalence of ED by BMI status

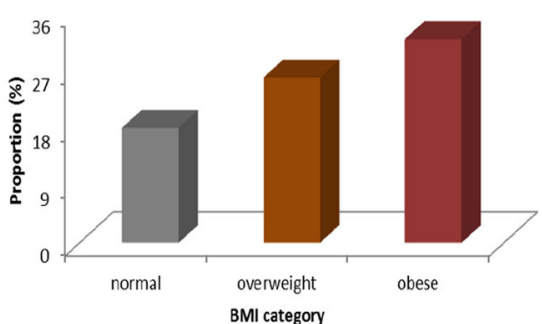

Prevalence of ED by Hypertension status

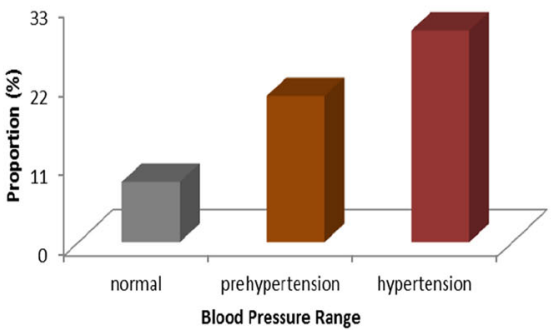

Fig. 1 Prevalence of ED by Age, BMI, Diabetes and Hypertension status

Chung et al [51] showed that obesity is not an underlying factor for ED per se, but it does increase the risk through development of chronic vascular disease. Numerous studies [12, 50,52-55] have suggested a dose dependent relationship between smoking and ED. Ever smokers in this study had a $40 \%$ increased likelihood for ED compared to never smokers. A systematic review by Cao [55] et al. found that ED was increased by $20 \%$ and $51 \%$ among past- and current-smokers respectively. Apart from its potential to cause direct toxic effects on the vascular endothelium, smoking is linked to ED through its potential to mediate systemic changes including hypercoagulability, platelet aggregation and thromboxane-prostacyclin imbalance [56].

Diabetes is a well-established factor for ED. Participants with diabetes in our study had a 5 times increased odds for ED (OR 5.3) compared to diabetes-free persons. These current results have replicated the findings of a study by Zedan [57] et al. among Egyptian men which found an odds of 5.4. Other studies have consistently

Table 2 Multivariate Logistic Regression Analysis of Factors Associated with ED

\begin{tabular}{lllll}
\hline Test group & Comparative group & OR & $95 \% \mathrm{Cl}$ & $P$-value \\
\hline Age $\geq 40$ & Age $<40$ & 5.0 & $2.2-11.2$ & $<0.001$ \\
BMI $\geq 30$ & $\mathrm{BMl}<30$ & 1.4 & $0.7-2.5$ & 0.306 \\
Hypertensive & Non-hypertensive & 1.2 & $0.6-2.3$ & 0.541 \\
Diabetic & Non-diabetic & 5.3 & $2.2-12.7$ & $<0.001$ \\
\hline
\end{tabular}

produced higher ED rates among diabetics compared to diabetes-free persons ranging between $35 \%$ and $75 \%[8$, $11,12,25,39,58-63]$. Diabetes is a risk factor for ED through its potential for causing autonomic neuropathy, gonadal dysfunction, and vascular and neurogenic impairment of penile smooth muscle [59, 64, 65]. Hypertensive participants had a tripled likelihood of having ED compared to their normotensive counterparts $(p<0.001)$, however the significance was lost after multivariate logistic analyses. Hypertension and some antihypertensive drugs have been shown to increase the risk for ED [17, 29]. High blood pressure is known to interfere with blood flow to the corpora cavernosa by causing narrowing and loss of elasticity of arteries thus resulting to ED [66].

Other factors including heavy alcohol consumption [2, 52], depression [18, 67-69], and low economic status $[18,70,71]$ have been associated with increased risk for ED but were beyond the scope of this study. Further studies on ED in this area could investigate on their association with ED among Tanzanian men.

This study has several strengths including; (i) the use of an internationally recognized tool for assessing ED that will make comparison with other studies feasible, (ii) the simultaneous assessment of obesity, diabetes and hypertension allowed us to confirm the presence of these risk factors rather than relying on participants' self-report. This study has some limitations as well, including; (i) the generalizability of our findings may be limited because the men screened in this study voluntarily came for screening 
and this might reflect a selected population of those either with a very good health seeking behavior or those having some health concerns necessitating medical help, (ii) Our assessment of ED was through interviews and we are aware that conditions like ED are highly associated with social stigmas. As a result of this, it is likely that ED was underreported by study participants, (iii) we made diagnoses of hypertension and diabetes based on a single point measurement of BP and RBG/FBG, thus our diabetes and hypertension rates might be overestimated, and (iv) our study was prone to several forms of bias including selection bias and non-differential bias, inevitably due to its cross-sectional nature.

\section{Conclusions}

Several conclusions can be drawn from this present study: (i) ED affects one in four men over 18 years in Kinondoni district, (ii) age and diabetes mellitus are the strongest factors associated with ED, (iii) the high rates of ED among hypertensive and diabetic patients suggest that patients with such comorbidities should be screened for ED, (iv) with the increasing incidence of obesity, hypertension, diabetes and an aging population, ED may become a significant public health problem. In view of these findings: (i) services for diagnosis and treatment of ED should be incorporated in diabetes and hypertension clinics particularly in the developing world, and (ii) health programs should be designed in developing nations to educate and empower individuals on healthy eating, physical activeness and health seeking behavior.

\section{Acknowledgement}

We are grateful to clinicians and nurses of the Jakaya Kikwete Cardiac Institute and Mwananyamala hospital for their dedication towards this study. The authors are indebted to Hon. Regional Commissioner Paul Makonda for the technical and financial support.

\section{Funding}

This study was funded by the Office of the District Commissioner for Kinondoni Municipal. The funder played no role in the design, analysis and manuscript development of this research. The authors assume the responsibility for this work.

\section{Availability of data and materials}

The final version of data set supporting the findings of this paper may be found in the Jakaya Kikwete Cardiac Institute website (http://www.jkci.or.tz). The corresponding author will be more than willing to email the data set to the editorial committee whenever it's needed.

\section{Authors' contributions}

MJ, PK, and PP made contributions in study designing. PP and PN performed all data management and manuscript writing. The initial draft was revised by PK, HM, NS and MJ. All authors contributed to and approved the final manuscript version.

\section{Competing interests}

The authors declare that they have no competing interests.

\section{Ethics approval and consent to participate}

Ethical clearance was obtained from the Unit of Research of the Jakaya Kikwete Cardiac Institute (JKCl). Permission to conduct the study was granted by the Office of the Kinondoni District Commissioner. All participating men gave informed consent.
Received: 30 March 2016 Accepted: 20 October 2016

Published online: 29 November 2016

\section{References}

1. Consensus NIH. Development Panel on Impotence. NIH Consensus Conference. Impotence. JAMA. 1993;270:83-90.

2. Moreira ED, Bestane WJ, Bartolo EB, Fittipaldi JAS. Prevalence and determinants of erectile dysfunction in Santos, southeastern Brazil. Sao Paulo Med J. 2002;120:49-54.

3. Krane RJ, Goldstein I. Saenz de Tejada I. Impotence. N Engl J Med. 1989:321:1648-59.

4. MacDonagh $R$, Ewings $P$, Porter $T$. The effect of erectile dysfunction on quality of life: psychometric testing of a new quality of life measure for patients with erectile dysfunction. J Urol. 2002;167(1):212-7.

5. Muneer A, Kalsi J, Nazareth I, Arya M. Erectile Dysfunction. BMJ. 2014;348:g129.

6. Kongkanand A. Prevalence of erectile dysfunction in Thailand. Thai Erectile Dysfunction Epidemiological Study Group. Int J Androl. 2000;23 suppl 2:77-80.

7. Braun $M$, Wassmer $G, K$ Klotz $T$, et al. Epidemiology of erectile dysfunction: results of the "Cologne Male Survey.". Int J Impot Res. 2000;12:305-11.

8. Martin-Morales A, Sanchez-Cruz JJ, Saenz TI, et al. Prevalence and independent risk factors for erectile dysfunction in Spain: results of the Epidemiologia de la Disfuncion Erectil Masculina Study. J Urol. 2001;166:569-74.

9. Klein $\mathrm{R}$, Klein $\mathrm{BE}$, Lee KE, et al. Prevalence of self-reported erectile dysfunction in people with long-term IDDM. Diabetes Care. 1996;19:135-41.

10. Fedele D, Coscelli C, Santeusanio F, et al. Erectile dysfunction in diabetic subjects in Italy. Gruppo Italiano Studio Deficit Erettile nei Diabetici. Diabetes Care. 1998;21:1973-7.

11. Fedele $D$, Bortolotti $A$, Coscelli $C$, et al. Erectile dysfunction in type 1 and type 2 diabetics in Italy. On behalf of Gruppo Italiano Studio Deficit Erettile nei Diabetici. Int J Epidemiol. 2000;29:524-31.

12. Moreira ED, Abdo $\mathrm{CH}$, Torres EB, et al. Prevalence and correlates of erectile dysfunction: results of the Brazilian study of sexual behavior. Urology. 2001;58:583-8.

13. Chew KK, Earle CM, Stuckey BG, et al. Erectile dysfunction in general medicine practice: prevalence and clinical correlates. Int J Impot Res. 2000;12:41-5.

14. Benet AE, Melman A. The epidemiology of erectile dysfunction. Urol Clin North Am. 1995;22:699-709.

15. Kolodny RC, Kahn CB, Goldstein HH, Bornett DM. Sexual dysfunction in diabetic men. Diabetes. 1974;13(4):306-9.

16. Lewis RW, Fugl-Meyer KS, Bosch R, et al. Epidemiology/risk factors of sexual dysfunction. J Sex Med. 2004;1(1):36-9.

17. Sáenz de Tejada I, Angulo J, Cellek S, et al. Pathophysiology of erectile dysfunction. J Sex Med. 2005;2(1):26-39.

18. Lockhat $Y$, Ross A, Ramlachan $P$, Rangiah C. The prevalence of erectile dysfunction at a primary healthcare clinic in Durban, KwaZulu-Natal, S Afr Fam Pract. 2013:55(3):289-93. doi:10.1080/20786204.2013.10874352.

19. Hirshkowitz M, Karacan I, Gurakar A, et al. Hypertension, erectile dysfunction, and occult sleep apnea. Sleep. 1989;12:223-32.

20. Metro MJ, Broderick GA. Diabetes and vascular impotence: does insulin dependence increase the relative severity? Int J Impot Res. 1999;11:87-9.

21. Wei M, Macera CA, Davis DR, et al. Total cholesterol and high density lipoprotein cholesterol as important predictors of erectile dysfunction. Am J Epidemiol. 1994;140:930-7.

22. Mckinlay JB, Longcope C, Gary A. The questionable physiologic and epidemiologic bases for a male climacteric syndrome: preliminary results from Massachusetts Male Aging Study. Maturitas. 1989;11:103-15.

23. Bortolotti A, Parazzini F, Colli E, Landoni M. The epidemiology of erectile dysfunction and its risk factors. Int J Androl. 1997;20:323-34.

24. Kirby R, Holmes S, Carson C. Erectile dysfunction. 2nd ed. Oxford: Health Press; 1998

25. Tan JK, Hong CY, Png DJC, Liew LCH, Wong ML. Erectile Dysfunction in Singapore: Prevalence and Its Associated Factors - A Population-Based Study. Singapore Med J. 2003:44(1):020-6.

26. Feldman HA, Goldstein I, Hatzichristou DG, et al. Impotence and its medical and psychosocial correlates: results of the Massachusetts Male Aging Study. J Urol. 1994;151:54-61.

27. Kedde $H$, Donker $G$, Leusink $P$, Kruijer $H$. The incidence of sexual dysfunction in patients attending Dutch general practitioners. Int J Sex Health. 2011;23(4):269-77. 
28. Adebusoye LA, Olapade-olaopa OE, Ladipo MM, Owoaje ET. Prevalence and Correlates of Erectile Dysfunction among Primary Care Clinic Attendees in Nigeria. Global J Health Sci. 2012;4(4):107-17.

29. El-Sakka Al, Tayeb KA. Erectile dysfunction risk factors in non-insulin dependent diabetic Saudi patients. J Urol. 2003;169:1043-7.

30. Pinnock CB, Marshall VR. Erectile dysfunction in the community: a prevalence study. Med J Aust. 1999;171(7):353-7.

31. Prins J, Blanker MH, Bohnen AM, Thomas S, Bosch JLHR. Prevalence of erectile dysfunction: a systematic review of population-based studies. Int J Impot Res. 2002;14:422-32.

32. Al-Hunayan A, Al-Mutar M, Kehinde EO, Thalib L, Al-Ghorory M. The prevalence and predictors of erectile dysfunction in men with newly diagnosed with type 2 diabetes mellitus. BJU Int. 2007;99:130-4.

33. Khatib FA, Jarrah NS, Shegem NS, Bateiha AM, Abu-Ali RM, Ajlouni KM Sexual dysfunction among Jordanian men with diabetes. Saudi Med J. 2006:27:351-6

34. Koskimaki J, Hakama M, Huhtala H, Tammela TL. Effect of erectile dysfunction on frequency of intercourse: a population based prevalence study in Finland. J Urol. 2000;164:367-70.

35. Dunn KM, Croft PR, Hackett Gl. Sexual problems: a study of the prevalence and need for health care in the general population. Fam Pract. 1998;15:519-24.

36. Ventegodt S. Sex and the quality of life in Denmark. Arch Sex Behav. 1998:27:295-307.

37. Mutagaywa RK, Lutale J, Aboud M, Kamala BA. Prevalence of erectile dysfunction and associated factors among diabetic men attending diabetic clinic at Muhimbili National Hospital in Dar-es-Salaam, Tanzania. Pan Afr Med J. 2014;17:227.

38. Selvin E, Burnett AL, Platz EA. Prevalence and risk factors for erectile dysfunction in the US. Am J Med. 2007;120(2):151-7.

39. Ayta IA, McKinlay JB, Krane RJ. The likely worldwide increase in erectile dysfunction between 1995 and 2025 and some possible policy consequences. BJU Int. 1999;84(1):50-6.

40. WHO. Physical status: the use and interpretation of anthropometry. Report of a WHO Expert Committee. WHO Technical Report Series 854. Geneva: World Health Organization; 1995.

41. American Diabetes Association. Classification and diagnosis of diabetes. Sec 2. In Standards of Medical Care in Diabetes_2015. Diabetes Care. 2015;38 Suppl 1:S8-S16.

42. Chobanian AV, Bakris GL, Black HR. Seventh report of the joint national committee on prevention, detection, evaluation, and treatment of high blood pressure. Hypertension. 2003;42:1206-52. Originally published online December 1, 2003.

43. Cappelleri JC, Rosen RC, Smith MD, et al. Diagnostic evaluation of the erectile function domain of the International Index of Erectile Function. Urology. 1999;54:346-51.

44. Rosen RC, Riley A, Wagner G, et al. The International Index of Erectile Function (IIEF): a multidimensional scale for assessment of erectile dysfunction. Urology. 1997;49(7):822-30

45. Rosen RC, Cappelleri JC. The sexual health inventory for men (IIEF-5). Int J Impot Res. 2000;12:342-3.

46. Rosen RC, Cappelleri JC, Smith MD, et al. Development and evaluation of an abridged, 5-item version of the International Index of Erectile Function (IIEF-5) as a diagnostic tool for erectile dysfunction. Int J Impot Res. 1999;11:319-26.

47. Bai Q, Xu Q, Jiang H, Zhang W, Wang X, Zhu J. Prevalence and risk factors of erectile dysfunction in three cities of China: a community-based study. Asian J Androl. 2004;6:343-8.

48. Seyam RM, Albakry A, Ghobish A, Arif H, Dandash K, Rashwan H. Prevalence of erectile dysfunction and its correlates in Egypt: a community-based study. Int J Impot Res. 2003;15:237-45.

49. Johannes $C B$, Araujo $A B$, Derby $C A$, et al. Incidence of erectile dysfunction in men 40 to 69 years old: longitudinal results from the Massachusetts male aging study. J Urol. 2000;163(2):460-3.

50. Corona G, Mannucci E, Mansani R, et al. Aging and pathogenesis of erectile dysfunction. Int J Impot Res. 2004;16(5):395-402.

51. Mannino DM, Klevens RM, Flanders WD. Cigarette smoking: An independent risk factor for impotence? Am J Epidemiol. 1994;140:1003-8.

52. Derby CA, Mohr BA, Goldstein I, Feldman HA, Johannes CB, McKinlay JB. Modifiable risk factors and erectile dysfunction: Can lifestyle changes modify risk? Urology. 2000;56:302-6.

53. Rosen RC. Brief male sexual function inventory for urology. Urology. 1996:47(5):782-3.
54. McVary KT, Carrier S, Wessells H. Subcommittee on Smoking and Erectile Dysfunction Socioeconomic Committee, Sexual Medicine Society of North America. Smoking and erectile dysfunction: evidence based analysis. J Urol. 2001;166:1624-32.

55. Cao S, Yin X, Wang Y, Zhou H, Song F, Lu Z. Smoking and Risk of Erectile Dysfunction: Systematic Review of Observational Studies with Meta-Analysis. PLoS One. 2013;8(4):e60443.

56. Bornman MS, du Plessis DJ. Smoking and vascular impotence: A reason for concern. S Afr Med J. 1986;70:329-30.

57. Zedan H, Hareadei AA, Abd-Elsayed AA, Abdel-Maguid EM. Cigarette smoking, hypertension and diabetes mellitus as risk factors for erectile dysfunction in upper Egypt. East Med Health J. 2010;16:281-5.

58. Kayigil $\mathrm{O}$, Atahan $\mathrm{O}$, Metin A. Multifactorial evaluation of diabetic erectile dysfunction. Int Urol Nephrol. 1996;28:717-21.

59. Cummings $M H$, Alexander WD. Erectile dysfunction in patients with diabetes. Hosp Med dysfunction. 1999;60:638-44.

60. McCulloch DK, Campbell IW, Wu F, et al. The prevalence of diabetic impotence. Diabetologia. 1980;18:279-83.

61. Kaiser FE, Korenman SG. Impotence in diabetic men. Am J Med. 1988:85:147-52

62. De Berardis G, Franciosi M, et al. Quality of Care and Outcomes in Type 2 Diabetes (QuED) Study Group. Erectile dysfunction and quality of life in type 2 diabetic patients: a serious problem too often overlooked. Diabetes Care. 2002;25(2):284-91.

63. Siu SC, Lo SK, Wong KW, et al. Prevalence of and risk factors for erectile dysfunction in Hong Kong diabetic patients. Diabetes Med. 2001;18:732-8.

64. Jevtich MJ, Edson M, Jarman WD, Herrera HH. Vascular factor in erectile failure among diabetics. Urology. 1982;19:163-8.

65. Saenz de Tejada I, Goldstein I, Azadzoi K, Krane RJ, Cohen RA. Impaired neurogenic and endothelium-mediated relaxation of penile smooth muscle from diabetic men with impotence. N Engl J Med. 1989;320:1025-30.

66. Sáenz de Tejada I, Goldstein I. Diabetic penile neuropathy. Urol Clin North Am. 1988;15(1):17-22.

67. Seftel AD. Erectile dysfunction in the elderly; epidemiology, aetiology and approaches to treatment. J Urol. 2003;169(6):1999-2007.

68. Kubin M, Wagner G, Fugl-Meyer AR. Epidemiology of erectile dysfunction. Int J Impot Res. 2003:15(1):63-71.

69. Berrada S, Kadri N, Mechakra-Tahari S, Nejjari C. Prevalence of erectile dysfunction and its correlates: a population based study in Morocco. Int J Impot Res. 2003;15 Suppl 1:S3-7.

70. Ahn TY, Park JK, Lee SW, et al. Prevalence and risk factors for erectile dysfunction in Korean men: results of an epidemiological study. Int J Sex Med. 2007;4(5):1269-76.

71. Aytaç IA, Araujo AB, Johannes CB, Kleinman KP, McKinlay JB. Socioeconomic factors and incidence of erectile dysfunction: findings of the longitudinal Massachussetts Male Aging Study. Soc Sci Med. 2000;51(5):771-8.

\section{Submit your next manuscript to BioMed Central and we will help you at every step:}

- We accept pre-submission inquiries

- Our selector tool helps you to find the most relevant journal

- We provide round the clock customer support

- Convenient online submission

- Thorough peer review

- Inclusion in PubMed and all major indexing services

- Maximum visibility for your research

Submit your manuscript at www.biomedcentral.com/submit 